\title{
Metodología e interpretación patrimonial del web de la Fundación El Legado Andalusí
}

\author{
Inmaculada Cortés Martínez \\ Técnico de la Fundación El Legado Andalusi
}

\section{CONSIDERACIONES PREVIAS}

Como no cesan de recordarnos, nos encontramos a las puertas de una nueva era. En todo el mundo, se están preparando múltiples actuaciones para marcar este paso simbólico hacia el nuevo milenio. En estos momentos examinamos objetivos y prioridades, evaluamos los recursos y volvemos a establecer nuevas alternativas. Frecuentemente la mayoría de todos estos discursos aparecen fortalecidos por la necesidad de reconocer y enfrentarse a nuevos retos.

En la actualidad, gracias a los nuevos hábitos del consumo y del tiempo libre, todos estamos asistiendo a un incremento paulatino del concepto de patrimonio como acepción social cada vez más utilizada.

A la vez y con mayor frecuencia, nos encontramos en los medios de comunicación con reportajes en que la palabra "Internet" aparece como elemento complementario y esencial dentro de todo este puzzle. Hace tan sólo unos años, Internet se representaba como el auténtico embrión de las autopistas de información de las que tanto se habla últimamente. Ahora la diferencia estriba en que ya no se trata de algo futurible, puesto que es una auténtica realidad utilizada a diario por millones de personas en el mundo.

Si analizamos de una forma breve el fenómeno de Internet podemos encontrar dos puntos de vista:

I. Desde el punto de vista técnico definimos Internet como un inmenso conjunto de ordenadores que se encuentran conectados entre sí, dando lugar a la mayor red de redes de ámbito mundial.

2. Desde un punto de vista más amplio Internet constituye un fenómeno sociocultural de importancia creciente. Una nueva forma de entender las comunicaciones que están transformando el mundo gracias a que millones de individuos a diario tienen acceso a esta inagotable fuente de información (la mayor que jamás haya existido), provocando un inmenso y continuo transvase de conocimientos.

En estos momentos, el objetivo último de la "Red" no es la mera conexión e intercomunicación entre millones de ordenadores, sino el servir de medio para que millones de usuarios de esos ordenadores lleven a cabo tareas útiles y necesarias de una forma mucho más eficiente y rápida. Internet se ha convertido en un elemento cotidiano de uso, y en ese sentido el mundo de la cultura no podía permanecer al margen.

La Red ha ido evolucionando hasta convertirse en un medio básico de divulgación de la información. Cada vez es más frecuente encontrar nuevos servicios de búsqueda, lugares temáticos, grupos de noticias o foros de discusión, por citar algunos ejemplos. En estos momentos de continuo despegue, Internet se ha consolidado y ha pasado a formar parte de nuestra actividad cotidiana, además de suponer un cambio en la organización del trabajo. Y sin duda el aspecto más notable es su rápido y vertiginoso crecimiento.

\section{EL WEB DEL LEGADO ANDALUSí}

Hace ya más de 4 años que la Fundación El Legado Andalusí, dependiente de la Junta de Andalucía e impulsada por las Consejerías de Cultura y Turismo, inició su primera andadura en la red utilizando para ello navegadores estándar del tipo WWW.

Conscientes de la importancia del uso de las nuevas tecnologías, desde finales de 1995 se empezó a trabajar en el diseño de la aplicación del Legado Andalusí, iniciando por primera vez su funcionamiento en junio de 1996:
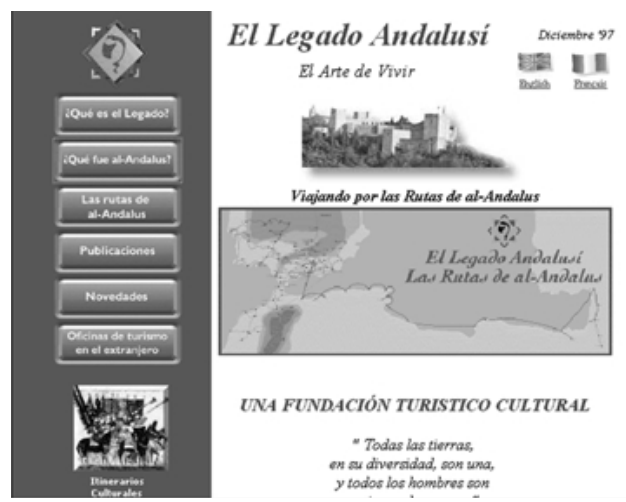

(http://www.legadoandalusi.es)

Partiendo de un determinado patrimonio (la historia de al-Andalus en nuestro caso), pretendemos sensibilizar al usuario-visitante ofreciendo claves generadoras de una lectura que permita ver, analizar, observar, sen- 
tir, comprender y revivir parte de la información que se le ofrece. El inmenso patrimonio de creatividad e ingenio que acumuló al-Andalus y del cual somos herederos es lo que reivindicamos para ponerlo al servicio de la más noble causa: la de la paz y el progreso, la de la conciencia y el entendimiento mutuo.

En este sentido El Legado Andalusí se ha erigido a modo de Centro de Interpretación que intenta divulgar un modelo comprensible y asimilable de nuestro actual patrimonio, relacionando el pasado histórico y su medio presente. Así, a través del concepto de Itinerario Cultural del Legado Andalusí (basado en hechos históricos reales de la civilización andalusí) se ofrecen nuevas posibilidades de desarrollo de un turismo cultural que sea capaz de difundir y dar a conocer un patrimonio y una historia común.

Con la idea de Itinerario Cultural no sólo hemos definido un recorrido real, una mera ruta, sino que hemos integrado ante todo la idea de símbolo de un "proceso de cooperación cultural" que implica la colaboración de todos.

Bajo el título de Itinerario Cultural de los Almorávides y Almohades, nos hemos propuesto guiar al viajero interesado en la historia, el arte y la cultura a través de los monumentos, los vestigios y los recuerdos tangibles del pasado que aún jalonan estos recorridos. El desarrollo de este Itinerario puede ser útil, y en eso confiamos, para concienciar a la colectividad sobre la protección de un patrimonio común que además de servir de testimonio claro, conmemora hechos y mentalidades realmente útiles para la transmisión de las identidades individuales y colectivas.

Creemos que es necesario crear una experiencia cultural despojada de demasiado academicismo. Tenemos que dejar que el patrimonio hable por sí mismo, que los vestigios cuenten sus secretos, que se despierten las sensaciones y en definitiva que la historia cobre vida.

Con la catalogación patrimonial elaborada, más que lograr la erudición monográfica se ha pretendido acercar al posible lector al conocimiento inmediato del territorio partiendo de un ámbito temático de primera instancia.

Partiendo de una documentación e información de carácter integrador que huye de una visión fragmentada, se han marcado criterios de catalogación monumental, creemos que satisfactorios, que han contado con la cooperación y colaboración científica de distintos organismos, instituciones y universidades.

Para su desarrollo hemos utilizado algunos instrumentos patrimonialistas consagrados por la vieja experiencia, que han tenido que ser revisados, examinados y valorados, optando en ocasiones por la utilización de nuevos enfoques y metodologías.

Como todos sabemos, la historia no es un ente absoluto. A través del tiempo, ha compartido interpre- taciones que frecuentemente han sido diferentes dependiendo de la ideología del momento. Por todo esto entre otras razones, creemos que se hace necesario ofrecer nuevas interpretaciones del patrimonio, aunque no invenciones y deformaciones. Si definir el patrimonio significa entenderlo, nuestra estrategia de interpretación histórica no podía llevarse acabo sin una reflexión abierta, racional y permanente, marcada por el rigor metodológico.

Proteger y difundir este legado cultural no debe significar solamente un acto físico, sino un proceso educativo en el cual la interpretación de nuestro patrimonio desempeña un papel esencial. Es sorprendente y generalizado en los medios educativos la ligereza con que se suele tratar en ocasiones el periodo de al-Andalus. Conocemos a los Fernandos, Alfonsos, Sanchos y en cambio desconocemos los Yusuf, Abd Allah o alAhmar, por citar algunos ejemplos.

Necesitamos hacer partícipe al visitante con los vestigios, las ruinas, los textos e incluso con los protagonistas de esa época. Si somos capaces de lograr esto, tal vez se comprendan muchos significados y se encuentren respuestas a muchas preguntas.

Interpretar, recuperar y presentar todo este patrimonio no es sólo beneficioso para la persona interesada, sino que es el mejor método para promover la protección y preservación de nuestro legado.

\section{Metodología en el desarrollo de las páginas web}

Desde un principio los objetivos teóricos que se pretendieron conseguir con el desarrollo de las páginas web del Legado se fundamentaban en los siguientes aspectos:

- Sistematización del programa teniendo en cuenta la estructura del Banco de Datos existente.

- Definición de especificaciones funcionales estandarizadas.

- Homogeneidad y unificación de criterios capaces de crear un sistema dinámico y flexible.

- Integración de diferentes entornos de información de una forma clara, precisa y atractiva.

- Coordinación de los flujos informativos, cargando y actualizando la información textual y gráfica.

- Realización de un importante diseño corporativo.

Dentro de este contexto se organizó el acceso a nuestras páginas web, que quedaron estructuradas siguiendo algunos de los siguientes epígrafes:

- Información institucional

- ¿Que fue al-Andalus? 
- Itinerarios Culturales

- Publicaciones

- Las Rutas de Al-Andalus

A la vez hubo que afrontar importante retos:

- Unificación de las líneas de investigación a seguir.

- Sistematización y normalización terminológica.

- Tratamiento integral con el fin de obtener una visión concisa e independiente.

- Ampliar algunos conocimientos sobre patrimonio que consideramos en muchos casos insuficientes.

Originariamente el lenguaje utilizado (HTML) se basaba en páginas de información donde se permitía la integración de imágenes y texto con enlaces hipertextuales entre páginas. Este tipo de acceso estático a la información ha ido evolucionando, de modo que actualmente ya es compatible y nos permite la integración de contenidos dinámicos (sonidos o animación)

A su vez, es importante tener en cuenta y no olvidar la manipulación interactiva de la información que nos permite realizar por parte del potencial usuario una consulta o gestión personalizada (a través del requerimiento de algún tipo de información). Otro factor que no podemos dejar de lado en el desarrollo de las páginas web es la visualización de los datos, puesto que no es sólo importante ver imágenes, sino favorecer la creación de espacios virtuales.

Para la mejora y optimización del desarrollo inicial fue necesario tener en cuenta:

I. Presentar una interacción adecuada a las necesidades existentes.

2. Agilizar las consultas mediante la indexación espacial de la información.

3. Integración de información multimedia.

4. Utilización de algoritmos de comprensión de la información para su transmisión por la red.

5. Optimizar la descarga de información.

6. Coordinar los flujos informativos, cargar y actualizar la información textual y gráfica.

A la hora de facilitar en la medida de lo posible la facilidad de acceso de toda la información se canalizó el sistema de tal forma que el usuario pudiera acceder de una forma sencilla. Para ello, nos centramos en aspectos relacionados con la representación de la información, navegación por la aplicación y accesibilidad a los diferentes tipos de consultas que pudieran realizarse para la obtención de la información deseada.

Dentro del contexto de creación de las páginas web, otro aspecto muy a tener en cuenta es la posibilidad de modificar parte de la aplicación para ajustarla a la diferentes tipos de situaciones. La capacidad adaptativa es obligada y necesaria dentro del diseño final.

Progresivamente estamos procediendo a la creación de sitios web multilingües (inglés, francés y árabe), dentro de la actual aplicación que en estos momentos ocupa aproximadamente $40 \mathrm{Mb}$.

El núcleo de todo se centraliza en la consecución y adaptación de unas Bases de Datos capaces de soportar toda la información de una forma heterogénea, adaptando los mecanismos disponibles a través de Internet para su presentación y acceso por parte de los usuarios del sistema.

Los nuevos sistemas de información electrónica además de ofrecer múltiples ventajas permiten la recepción de informaciones hacia los centros de emisión.

Eso significa que el visitante-usuario además de ser consumidor, es a su vez fuente de información, posibilitando así la obtención de datos que en algunas ocasiones pueden ser extremadamente útiles.

En la actualidad podemos saber el número de usuarios que visitan nuestras páginas web, secciones más consultadas, tiempo medio dedicado en cada visita, nacionalidad de los visitantes, nivel de actividad por día de la semana, nivel de actividad por horas del día, promedio de impresiones de cada página, usuarios más asiduos, etc. A título de ejemplo y si observamos el siguiente cuadro, podemos ver clasificados por tipo de organización a los distintos usuarios que visitan las páginas de la Fundación:

\section{ACTIVIDAD POR TIPO DE ORGANIZACIÓN}

\begin{tabular}{rrr}
\hline & Organización & $\%$ del total \\
\hline 1 & Compañía & $47.49 \%$ \\
\hline 2 & Red & $33.36 \%$ \\
\hline 4 & Educación & $13.87 \%$ \\
\hline 5 & Arpanet & $2.03 \%$ \\
\hline 6 & Organización & $1.70 \%$ \\
\hline 7 & Gobierno & $0.76 \%$ \\
\hline 8 & Otros & $0.6 \%$ \\
\hline & Militar & $0.15 \%$ \\
\hline
\end{tabular}

Esto incluye los sufijos como .com, net, .edu, mil, .org, gov y us. La tabla muestra todos los tipos de organizaciones ordenadas por cantidad de accesos. 
Todos estos datos permiten sin duda definir claramente el perfil de nuestros visitantes: conocer los países más activos, comprobar los datos que más interesan, suprimir o ampliar determinadas secciones, estudiar la necesidad de potenciar el web en un determinado idioma, identificar las organizaciones que frecuentemente acceden a la aplicación, etc.

En estos momentos El Legado Andalusí trabaja ya en el diseño de nuevas y novedosas páginas web que en breve se incorporarán a la red. Además de mantener la aplicación actual, está prevista la inclusión de nuevas secciones renovables con abundantes links que facilitarán al usuario el acceso a otras páginas relacionadas con la actualidad política, económica, cultural y social.

\section{REFLEXIÓN}

Tratamos, en definitiva, de promover un conjunto de experiencias capaces de ofrecer al público un significado y una convivencia. A través de la presentación de la información de una forma amena e interesante, hemos intentado desarrollar una serie de servicios culturales orientados hacia un visitante que cada vez es más consciente de la calidad de la experiencia. La recuperación, conservación y difusión del patrimonio no debe ser tarea de unos pocos, sino que es obligación de todos nosotros. No se trata sólo de conservar nuestro pasado, sino de proteger también nuestro futuro.

\section{Bibliografía}

ARAQUE CUENCA, F., GUTIÉRREZ VELA, F., Internet buscando información. Dep. Lenguajes y Sistemas Informáticos, Universidad de Granada, junio 1996

BOSQUE SENDRA, J. Sistemas de información Geográficos, Madrid, 1992.

CRUCES RODRÍGUEZ, A., "Xipnet. Un proyecto integral de Red Informática distribuida para la difusión del patrimonio cultural y artístico de la comunidad valenciana". Cuadernos IAPH, VI, 1996.

ESEBBAG BENCHIMOL C., MARTÍNEZ VALERO, J., Internet, Madrid, 1996.

FAINSTEIN LAMUEDRA, G., MENDOZA GARCÍA. "Isabel". El Impacto de Internet en el trabajo profesional del documentalista: contrastes y perspectivas". Actas de las $\checkmark$ Jornadas españolas de documentación automatizada.

\section{Cáceres, FESABID, 1996.}

GILSTER, P., El navegante en Internet, 1995.

LIMÓN RODRÍGUEZ, S., ORTEGA VAQUERO, I., "El servidor Web del Instituto Andaluz de Patrimonio Histórico". Boletín del IAPH, 19. Junio, 1997.

MARTÍN GUGLIELMINO, M. "Reflexiones en torno a la difusión del patrimonio histórico". Cuadernos del IAPH, VII, 1996.

SIVAN, R., "El futuro del pasado. El producto turístico y la conservación de los bienes culturales". Cuadernos del IAPH, VII, 1996. 